\title{
Influence of Project Team Knowledge Diversity on Implementation of Building Construction Projects. A Case of Kajiado County, Kenya, Africa
}

\author{
Benson N. Leyian ${ }^{1}$, Prof. Charles M. Rambo ${ }^{1} \&$ Dr. Angeline Mulwa ${ }^{1}$ \\ ${ }^{1}$ School of Open and Distance Learning, University of Nairobi, Kenya \\ Correspondence: Benson N. Leyian, School of Open and Distance Learning, University of Nairobi, Kenya. E-mail: \\ ntoyianleyian@gmail.com
}

Received: August 11, 2021

Accepted: September 18, 2021

Online Published: September 20, 2021

doi:10.5539/jsd.v14n5p99

URL: https://doi.org/10.5539/jsd.v14n5p99

\begin{abstract}
Implementation of the building construction projects is done by workers with diverse knowledge. The knowledge diversity can either be beneficial or detrimental to the implementation process. Out of the 50 building construction projects implemented by Kajiado county government in the financial year 2016/2017, 24 were not successfully implemented. This study sought to determine the influence of project team knowledge diversity on the implementation of building construction projects. The study used a pragmatism paradigm as well as a correlational research design and a sample of 251 respondents. Data was collected using semi-structured questionnaires, interview guides, and observation. Quantitative data was analysed for means and standard deviation as well as inferential techniques for correlation and regression while hypothesis was tested using ANOVA. Qualitative data was thematically analysed and the results triangulated with the quantitative results for presentation. The results indicated the existence of a positive correlation $(r=0.323)$ between project team knowledge diversity and implementation of building construction projects. It was also established that $10.4 \%$ of the variations in implementation of the building construction projects are attributable to project team knowledge diversity $R^{2}=$ 0.104 . The null hypothesis project team knowledge diversity has no significant influence on implementation of building construction projects was rejected based on $F(1,219)=25.522, p=0.0000<0.05$. It was concluded that project team knowledge diversity has a significant influence on implementation of building construction projects. The study recommends that recruitment into project teams for implementation of building construction projects should consider people with diverse knowledge backgrounds since they complement each other's competencies.
\end{abstract}

Keywords: project team knowledge diversity, relationship conflict, task conflict, project implementation

\section{Introduction}

The building construction industry plays a key role in economic development since it is linked to several areas of the economy. To cater for the ever-increasing population, pressure on land, and growing economic activity, building construction projects have increased in demand (Zhang, Xiaoling, Yuzhe, Liyin, \& Martin, 2014). The last few years have seen an increase in the number of studies on the effect of project team knowledge diversity on the implementation construction projects. There have been mixed results with respect to the interactions between project team knowledge diversity and implementation of construction projects. Some studies have indicated that knowledge diversity among project team members can result in introduction of new knowledge and hence enhance the process of implementation (Chan et.al., 2017) while others such as Lovelace and Shapiro (2001) indicate a negative relationship between project team knowledge diversity and performance of construction projects, in that the diversity could lead to conflict among the project members and hence be detrimental to the implementation of the construction projects. Additionally, some researchers such as Jetten et.al., (1998) claimed an inverted U-shaped kind of relationship existed between project team knowledge diversity and implementation of construction of projects.

The measurement of successful implementation of building construction projects has been a conceptualised by several researchers. For example, Ofori (2013) claims that a building construction project will be considered to have been successfully implemented if it meets its technical goals without moving away from the iron triangle 
measures of time, budget and scope. Van Nekerk and Steyn (2011) in their study done on construction projects in South Africa agree with the findings of studies done by other researchers such as Yalegama, Chileshe, and Ma (2016) and Thiong'o and Muchelule (2017) that there do not exist universal measures for project implementation success. They argue that it is important for the project management to determine the dimensions of success relative to their project before the start of implementation.

Kariuki (2018) observed that in Kenya, approximately $48 \%$ of projects report a cost overrun and 87 per cent of projects have a time overrun. The study largely attributed the failures to irrational project contracts that do not put into consideration all factors that lead to time delays. The fact that rural building construction project still experience overruns and that they are being attributed to poor project team management necessitates a need to establish how project team knowledge diversity influences project implementation. Kajiado county government implemented 50 building construction projects in the financial year 2015/2016 across its several administrative wards with a view of improving the living standards of the locals. Almost half of the projects implemented (24 projects) were not successfully implemented as per the report presented to the county government. Some of them were not finished in time, they could not meet the quality specification and they also exceeded the budget allocation.

\subsection{Implementation of Building Construction Projects}

The measurement of successful project implementation is a topic of debate in project management circles. For a building construction project to be considered successfully implemented one has to look at the initial project goals regarding project time, completion of the implementation within budget and satisfaction of the project stakeholders, then measure the extent to which each of them has been individually attained. Klagegg et.al., (2005) argue that the debate on the measurement of implementation of construction projects is far from being conclusive. This is because the measurement perspectives of the stakeholders vary depending on what they considered as a successful implementation of a building construction project. Nevertheless, researchers such as Ahsan and Gunawan (2010) insist that the best measures of successful project implementation are the aspect of project implementation within time and budget as well as meeting the project's quality specification.

In an attempt to develop a criterion for measuring project implementation success, Diallo and Thuilleir (2004) described a broad set of indicators that included project beneficiary's satisfaction, attainment of the set-up objectives of the project, the ability of a project to receive a good rating from the principal donors, and meeting the iron triangle conditions of being completed within time, budget, and scope. The implication of this criterion is that the categorization of project implementation success is pegged on the type of stakeholder as well as the sector in which project implementation is being measured. One of the most common measures of project implementation success is the project cost. The measurement of project cost is usually taken as a variance between the budgeted cost and the actual cost of the project. Lim and Mohamed (1999), claim that the duration that a project takes is considered to be a critical factor in measuring successful project implementation by both the project owners and the stakeholders. It is believed that a project that is not completed within the scheduled time was not running smoothly as expected.

Liu and Walker (1998) claim that satisfaction is a key indicator of successful implementation of building construction projects. The element of quality is fundamental in every stage of the building construction projects since it guarantees that the entire project will achieve the highest quality standard specified by the project owner. Chan, Chan and Chiang (2004) defined quality in building construction projects as the summation of features that a product requires so as to satisfy a given purpose or need. Measurement of quality in project planning is a subjective subject. Freeman and Beale (1992) in their study added the aspect of a project meeting its technical specification as an additional facet of quality. Traditionally, the measures of project implementation success have been budget, scope, time, and meeting quality specification (Barclay and Osei-Bryson, 2010; Wi and Jung, 2010). While there exist several acceptable measures of success in project implementation, this research will measure project implementation success using time taken to finish the project, the quality of the project delivered to the client, the project being finished with the planned budget, and lastly the project meeting the workers and client's satisfaction level.

\subsection{Project Team Knowledge Diversity and Implementation of Building Construction Projects}

Knowledge refers to a set of ideas that an individual possesses at any particular time. Knowledge is dynamic, in the sense that it grows depending on a person's exposure. Hu (2009) states that knowledge is gotten from thinking and it combines insights, experience, and information. A vast number of researches have indicated that the interaction of people who have different expertise levels, experiences, as well as knowledge helps in transferring knowledge from one person to another. The promotion of learning and innovation is achieved due to the exposure of the individuals to new perspectives and paradigms in addition to cross-fertilisation of ideas. A study done by 
Dulaimi (2005) argues that knowledge diversity among team members is important since it promotes innovation and creativity that are key project implementation aspects. The study further indicates that while setting up a project team, the experience of the team members show be taken care of, since a team consisting of people with experience in building construction project implementation will have an expansive knowledge and skills pool that come in handy during implementation of building construction projects.

Ogubazghi and Muturi (2014) did a study on the influence of education level of project directors on the implementation of construction projects. The study reports a negative effect of the educational level of project directors on implementation of construction projects and argue that the negative relationship between the education level diversity and implementation of construction projects could have been brought about by conflict of ideas between the project team members. Kristinsson et al. (2016) in their study on the association between knowledge diversity and performance of innovation teams, established a direct relationship between the two variables. Knowledge diversity was associated with generation and implementation of new ideas. Another study by Naqvi et al. (2013) posited that diversity in knowledge among team workers leads to application of fast and quality solutions in project implementation. Lee and Pillutla (2017) in their study on effect of heterogeneity in teams on performance observed that teams that are dissimilar in terms of learning and motivation abilities perform better than teams that are similar since low ability individuals strive to provide equal performance as their high ability counterparts.

A study was conducted by Myaskovsky et al., (2005) to determine the effect of training method on the performance and behaviours of small teams involved in the assembly of radios. They established that it took a lot of time to assemble radios in addition to making many errors for teams that had been trained together as compared to teams that had not been trained together. These findings highlighted the fact that when project workers are separately trained, they rely on beliefs and stereotyping to identify each other. Buyl, Boone, and Matthyssens (2013) in their study on the relationship between knowledge diversity and organisational ambidexterity found the existence of a direct relationship between the two variables. Diversity in qualifications and skills of individuals is key in the accomplishment of several tasks by teams (Dulaimi, 2005). While contributing to this debate Copen and Silverstein (2008) added that limitations of education among project team members can be compensated for by experience and on-job training. Notably, these are the same project team knowledge diversity factors considered in the current study albeit based on implementation of building construction project context in Kenya, a case of Kajiado County.

Khan (2012) did a study on the impact of training on employees' performance, it was established that training is a key contributor to performance of employees in an organisation. While looking at the influence of workplace diversity on the performance of employees at a university, Ahmad and Rahman (2019) observed that experience diversity which has been conceptualised in the current study as an aspect of knowledge diversity has a positive and significant influence on the performance of employees at the university. This implies that for the employees to perform better, it is important that different experience levels are gelled. Diversity in terms of knowledge pushes creativity and performance among members in a project team, diverse teams are more likely to achieve their targets with minimal errors as compared to teams that are homogeneous in knowledge (DiTomaso, 2007). Teams that are made up of individuals with a latitude of functional experience have a higher chance of being more productive since team members can easily overcome communication barriers because they understand each other's functions (Bunderson and Sutcliffe, 2002). This is supported by Cox (2001) who posited that skills diversity creates a large pool of ideas that can help come up with new and improved products. Valls, González - Romá, and Tomás (2016) looked at the relationship between education diversity and performance. They found a positive relationship existed between performance and education diversity, this implied that the more diverse a team is in terms of education, the more likely they are to achieve their objectives based on their performance measurement metrics.

A plethora of research on knowledge diversity have generally indicated a positive relationship between performance and knowledge diversity. For instance, Huang, Hseih, and He, (2014) indicated that diversity in terms of knowledge encouraged the members to acquire knowledge, skills, and expertise from each other. Researchers have shown that knowledge diversity increases the team members mutual understanding which motivates them to want to learn from each other thus broadening their scope of knowledge, which in turn helps in improving the project implementation process (Gong, Kim, Zhu, and Lee, 2013; Huang, Hsieh, and He, 2014). This implies that with increased diversity in knowledge, there will be several ideas, expertise, and perspectives that can help generate creative and novel ideas that enhance the implementation process (Shin et al., 2012). Empirical evidence additionally suggests that a team can develop its creative potential by sharing skills, expertise, and knowledge among the team members (Bodla et al., 2018). This study sought to find out the effect of project team knowledge diversity on the implementation of building construction projects in Kenya, a case of Kajiado County. 


\section{Theoretical Framework}

This study was premised on Ecosystem theory which was formally defined by Sir Arthur Tansley and put into application in the context of organisations by Odum (1953). According to the ecosystem theory, in every ecosystem there exists a symbiotic relationship characterised by diversity and mutual dependence. Competition plays a key role in the interdependence and diversity, but cooperation among the ecosystem members enhances creativity and innovation so as to help maintain sustainable development in the biological world. In the building construction context, this theory explains the relationships that exist between the different players involved in implementation of the project.

Project team members form a human ecosystem with diversity in knowledge and this is central to the existence of the human ecosystem. These associations when put together form a social order system. Machlis et.al., (1997) argue that, the social order subsystem incorporates some three fundamental mechanisms for behaviour ordering that is; personal identities (knowledge), norms (rules for behaving), and hierarchies (of wealth or power). Therefore, expectations are bound to arise as the team members interact during the implementation of the building construction projects, particularly when a member of the project team notes the existence of differences in education level, skills, and even power, such expectation allow the proper functioning of the social sub system. This therefore further informs this study that at the building construction setting whereby diversities as varied as they may be, provide a closely neat and sustainable environment among the project team members where they can share, interact and develop as a team. Combining this social order subsystem and implementation of building construction projects, results into a human ecosystem. The adaptation to such a system would either foster or derail the process of implementation of building construction projects hence a reason why in this study, it was determined to establish how the interactions of the workers with diversity in knowledge within the construction setup, influences the process of implementation of building construction projects.

\section{Conceptual Framework}

This study will be governed by the following relationship

\section{Independent Variable}

$\begin{array}{cl}\text { Knowledge Diversity } \\ \circ & \text { Team member education level } \\ \circ & \text { Team member specialty } \\ \circ & \text { Team member skills } \\ \circ & \text { Team member experience }\end{array}$

\section{Dependent Variable}

Implementation of Building Construction Projects

- Project completion within time

- Project completion within budget

- Stakeholder satisfaction

$\circ \quad$ Quality of project

Interpersonal Conflicts

○ Task conflict

○ Relationship conflict

Moderating Variable

Figure 1. Conceptual framework

In figure 1, the dependent variable is implementation of building construction projects, this is operationalized by considering the time taken to complete the project, the project budget, satisfaction of the stakeholders, and the final quality of the completed projects. The independent variable is knowledge diversity, which is operationalized as education level of project team members, their specialty, skills, and prior experience in implementation of building construction projects. It is assumed that project team knowledge diversity has an influence on the process of implementation of building construction projects. Interpersonal conflict has been taken as the moderating variable. 


\section{Research Methodology}

The study was guide by pragmatism paradigm and adopted descriptive cross-sectional survey and correlational research designs given that the nature of the study required both quantitative and qualitative data and testing on hypothesis. The target population consisted of 659 people made up of the county projects manager, county projects engineer, and project staff. A sample of 257 respondents was drawn from the target population of 659 using Yamane (1967) formula. The study used questionnaires and interview guides as the main instruments of data collection. Pilot testing, validity, and reliability of research instruments were done as recommended by Rutterford, Copas, and Eldridge (2015), Bhattacherjee (2012), and Mugenda and Mugenda (2012).

Data collected were analyzed using descriptive and inferential statistics. Descriptive statistics were used to analyze quantitative data using frequencies, percentages, means, and standard deviation while qualitative data were analyzed thematically then presented using narrative statements for each objective. Inferential statistics were used for hypothesis testing using correlational analysis, while regression analysis was used to establish how project team knowledge diversity is a good predictor of the change in implementation of building construction projects.

\section{Results and Discussion}

The data were analyzed and the results presented and discussed as per the following thematic areas:

\subsection{Questionnaire Return Rate}

Questionnaires were administered to a sample size of 251 workers spread out in the construction sites in Kajiado County. Out of 251 questionnaires for workers, 235 of them were filled and returned for analysis. But, 14 of the returned questionnaires were not usable for analysis since they were incomplete. The response rate for the sample was computed as $88.04 \%$, this was considered to be sufficient for analysis and statistical generalization. According to Saunders et al (2003) a response rate of 30-50\% is representative enough for statistical generalizations. Mugenda and Mugenda (2003) further add that response rates of $50 \%$ are acceptable for analysis and reporting while response rates of more than $60 \%-69 \%$ are regarded to be good and anything above $70 \%$ is excellent. Since this return rate is above the $70 \%$ recommended by Mugenda and Mugenda (2003), the study proceeded.

\subsection{Demographic Profiles of the Respondents}

Demographics of the respondents are discussed in terms of gender, age, education level, and period involved in implementation of building construction projects.

\subsubsection{Distribution of Respondents by Gender}

The respondents were asked to indicate their gender. This was to help determine the gender ratios involved in the building construction projects implementation process. The results are shown in Table 1.

Table 1. Distribution of respondents by gender

\begin{tabular}{lccr}
\hline Gender & Frequency & Cumulative Frequency & Percent \\
\hline Male & 192 & 192 & 86.9 \\
Female & 29 & 221 & 13.1 \\
Total & 221 & & 100 \\
\hline
\end{tabular}

Table 1 it indicates that majority of the participants in building construction projects implementation are male since from the 221 study respondents $192(86.9 \%)$ were male while $29(13.1 \%)$ were female. This is against the provisions of the Kenyan constitution, which stipulate that in an employment setting one gender should not be more than a third of the total. However, it confirms the long-known belief that building construction jobs are heavily manual and mostly a preserve of the male gender, who have the energy to implement the building construction projects successfully.

\subsubsection{Distribution of Respondents by Age}

The respondents were asked to indicate their age group. This was important since it would enable the researcher know whether all adult age-groups had equal chance of participation in the process of implementation of projects, or the employers had a preference for a certain age-group. The ages were put into six classes. The results are shown in Table 2. 
Table 2. Distribution of respondents by age

\begin{tabular}{lccr}
\hline Age Bracket & Frequency & Cumulative Frequency & Percent \\
\hline $18-25$ & 13 & 13 & 5.9 \\
$26-30$ & 118 & 131 & 53.4 \\
$31-35$ & 42 & 173 & 19 \\
$36-40$ & 26 & 199 & 11.8 \\
$41-45$ & 13 & 212 & 5.9 \\
Over 45 & 9 & 221 & 4.1 \\
Total & 221 & & 100 \\
\hline
\end{tabular}

Table 2 indicates that out of the 221 respondents who participated in the study $13(5.9 \%)$ fell in the age bracket $18-25$ years, $118(53.4 \%)$ were between $26-30$ years, $42(19 \%)$ fell between $31-35$ years, $26(11.8 \%)$ were between $36-40$ years, $13(5.9 \%)$ fell between $41-45$ years while $9(4.1 \%)$ were aged over 45 years. These results indicate that out of the 221 respondents $173(78.3 \%)$ were aged between 18-35 years, this shows that majority of the workers in the building construction projects in Kajiado County were youth who would be enthusiastic in participating in the study and have the energy to implement the building construction projects well.

\subsubsection{Distribution of Respondents by Highest Level of Education}

The study also aimed at establishing the level of education of the respondents who participated in the study. This was important since it had implications on how the respondents responded to questions and how well they understood the variables in the study. The respondents were asked to indicate the highest level of education obtained. The results are represented in Table 3.

Table 3. Distribution of respondents by highest level of education

\begin{tabular}{lccr}
\hline Highest level of education & Frequency & Cumulative Frequency & Percent \\
\hline Primary & 45 & 45 & 20.4 \\
Secondary & 100 & 145 & 45.2 \\
Certificate in Building & 48 & 193 & 21.7 \\
Diploma & 28 & 221 & 12.7 \\
Total & 221 & & 100 \\
\hline
\end{tabular}

Table 3 indicates that $45(20.4 \%)$ of the respondents had primary education qualification, $100(45.2 \%)$ had secondary school education, 48(21.7\%) had building certificate level qualification and 28 (12.7\%) had diploma qualification. The results showed that majority of the construction workers did not have any formal education in the respective areas of their work especially the higher education. Out of the 221 respondents those who had secondary level education, building certificate level education, and diploma education were 176(79.6\%), this showed that they were capable of understanding the questions well and provide good responses. Additionally, the education level would make them capable of understanding the instruction well and hence be capable of implementing the construction of building construction projects effectively.

\subsubsection{Distribution of Respondents by Period Worked in the Building Construction Industry}

The respondents were asked to indicate the duration they had spent working in projects dealing with implementation of building construction. This was considered necessary since it would indicate the level of understanding the respondent had in implementation of building construction projects. The responses are shown in Table 4. 
Table 4. Distribution of respondents by period worked in the construction company

\begin{tabular}{lccr}
\hline Period worked & Frequency & Cumulative Frequency & Percent \\
\hline Less than 5 years & 63 & 63 & 28.5 \\
$5-10$ years & 105 & 168 & 47.5 \\
$10-15$ years & 36 & 204 & 16.3 \\
$15-20$ years & 13 & 217 & 5 \\
Over 20 years & 4 & 221 & 1.8 \\
Total & 221 & & 100.0 \\
\hline
\end{tabular}

The results in Table 4 show that those who had worked for 5 years and less were 63 (28.5\%) and those worked between 5 - 10 years were 105 (47.5\%), while those who had worked between $10-15$ years were $36(16.3 \%)$. Those who had worked between $15-20$ years were $13(5.9 \%)$ and those worked for over 20 years were $4(1.8 \%)$. This result shows that majority of the respondents at $71.5 \%$ had worked in building construction projects for more than 5 years hence they had enough information to adequately and objectively respond to research questions on project team diversity at their work place. The experience of more than 5 years attained by the respondents makes them understand well the building construction implementation process hence increasing their efficiency.

\subsection{Implementation of Building Construction Projects}

The dependent variable in this study was the process of implementation of the building construction projects. Respondents were required to respond to questions in the questionnaire by indicating their level of agreement with the presented statements. Eleven (11) statements were presented and measured on a Likert-scale that contained 5points, that is $5=$ Strongly Agree (SA), $4=$ Agree (A), $3=$ Neutral (N), $2=$ Disagree (D) and $1=$ Strongly Disagree (SD). Mean and standard deviation for all the statements were computed and additionally, the composite mean and composite standard deviation were also computed. Finding results are shown in Table 5. 
Table 5. Implementation of building construction projects

\begin{tabular}{|c|c|c|c|c|c|c|c|c|}
\hline & Statements & SA & A & $\mathrm{N}$ & $\mathrm{D}$ & SD & Mean & $\begin{array}{l}\text { Std. } \\
\text { Dev }\end{array}$ \\
\hline \multirow[t]{2}{*}{1} & We complete tasks within time schedule & 64 & 132 & 10 & 6 & 9 & 4.07 & 0.90 \\
\hline & & $29.0 \%$ & $59.7 \%$ & $4.5 \%$ & $2.7 \%$ & $4.1 \%$ & & \\
\hline \multirow[t]{2}{*}{2} & We have few change requests by the client & 44 & 161 & 0 & 4 & 12 & 4.00 & 0.87 \\
\hline & during construction & $19.9 \%$ & $72.9 \%$ & $0.0 \%$ & $1.8 \%$ & $5.4 \%$ & & \\
\hline \multirow[t]{2}{*}{3} & We experience project delays during & 35 & 87 & 16 & 38 & 45 & 3.13 & 1.42 \\
\hline & construction & $15.8 \%$ & $39.4 \%$ & $7.2 \%$ & $17.2 \%$ & $20.4 \%$ & & \\
\hline \multirow[t]{2}{*}{4} & Tasks are completed within budget & 16 & 134 & 41 & 30 & 0 & 3.62 & 0.81 \\
\hline & & $7.2 \%$ & $60.6 \%$ & $18.6 \%$ & $13.6 \%$ & $0.0 \%$ & & \\
\hline \multirow[t]{2}{*}{5} & Minimal project variation orders are received & 21 & 164 & 17 & 12 & 7 & 3.81 & 0.80 \\
\hline & & $9.5 \%$ & $74.2 \%$ & $7.7 \%$ & $5.4 \%$ & $3.2 \%$ & & \\
\hline \multirow[t]{2}{*}{6} & We have minimal rework on the tasks already & 34 & 62 & 26 & 63 & 36 & 2.98 & 1.36 \\
\hline & completed & $15.4 \%$ & $28.1 \%$ & $11.7 \%$ & $28.5 \%$ & $16.3 \%$ & & \\
\hline \multirow[t]{2}{*}{7} & We meet quality specifications on & 73 & 131 & 0 & 6 & 11 & 4.13 & 0.94 \\
\hline & construction projects & $33.0 \%$ & $59.3 \%$ & $0.0 \%$ & $2.7 \%$ & $5.0 \%$ & & \\
\hline \multirow[t]{2}{*}{8} & Quality checks of materials is carried out & 80 & 120 & 6 & 9 & 6 & 4.17 & 0.88 \\
\hline & & $36.2 \%$ & $54.3 \%$ & $2.7 \%$ & $4.1 \%$ & $2.7 \%$ & & \\
\hline \multirow[t]{2}{*}{9} & County government is satisfied with our work & 72 & 134 & 4 & 5 & 6 & 4.18 & 0.81 \\
\hline & performance & $32.6 \%$ & $60.6 \%$ & $1.8 \%$ & $2.3 \%$ & $2.7 \%$ & & \\
\hline \multirow[t]{2}{*}{10} & We meet the client requirements/needs & 109 & 100 & 0 & 6 & 6 & 4.36 & 0.85 \\
\hline & & $49.3 \%$ & $45.3 \%$ & $0.0 \%$ & $2.7 \%$ & $2.7 \%$ & & \\
\hline \multirow[t]{3}{*}{11} & I am satisfied with the management of this & 96 & 113 & 2 & 4 & 6 & 4.31 & 0.82 \\
\hline & project & $43.4 \%$ & $51.2 \%$ & $0.9 \%$ & $1.8 \%$ & $2.7 \%$ & & \\
\hline & Composite Mean and Std. Dev. & & & & & & 3.89 & 0.46 \\
\hline
\end{tabular}

Table 5 shows that out of 221 respondents who participated in the study on statement 1 - we complete tasks within time schedule during implementation, $64(29 \%)$ of the respondents strongly agreed, $132(59.7 \%)$ agreed, $10(4.5 \%)$ were neutral, $6(2.7 \%)$ disagreed and $9(4.1 \%)$ strongly disagreed. The overall mean score was 4.07 with a standard deviation of 0.90 . This mean indicates that majority of the respondents agreed with the statement that building construction projects in Kajiado County are usually finished within the given time schedule. This line item mean of 4.07 was higher than the composite mean of 3.89 meaning completion of project tasks influenced implementation of building construction projects. However, the higher line item standard deviation of 0.90 than the composite standard deviation of 0.46 shows there were divergent views among the respondents.

Information sought from the respondents in statement 2 , that we received few change requests during project implementation, 44(19.9\%) of the respondents strongly agreed, 161(72.9\%) agreed, 4(1.8\%) disagreed and $12(5.4 \%)$ respondents strongly disagreed. The mean response for the statement was 4.00 and a standard deviation of 0.87 , indicating that the respondents agreed with the statement. This shows that there were few change requests by clients during the implementation of building construction projects. This line item mean of 4.00 was higher than the composite mean of 3.89 implying that fewer change requests were received, thus encouraging implementation of building construction projects. However, higher line item standard deviation of 0.87 than the composite standard deviation 0.46 shows there were divergent views from the respondents.

Statement 3, we experienced project delays during constructions, 35(15.8\%) respondents strongly agreed, $87(39.4 \%)$ agree, $16(7.2 \%)$ were neutral, $38(17.2 \%)$ disagreed while $45(20.4 \%)$ strongly disagreed. This resulted in a mean score of 3.13 and a standard deviation of 1.42. The mean indicates that the respondents were neutral, but with a standard deviation of 1.42 , this shows large variation from the mean, hence the responses were spread far 
away from the mean response. This ideally shows that the number of those who agreed and those who did not agree with the statement were almost equal. The higher line item standard deviation of 1.42 shows that there were strong divergent opinions compared with composite standard deviation of 0.46 that the project experienced delays during implementation.

Statement 4, that tasks are completed within budget, 16(7.2\%) strongly agreed, 134(60.6\%) agreed, 41(18.6\%) were neutral, and 30(13.6\%) disagreed. The mean for line item was 3.62 with a standard deviation of 0.81 . This mean was however lower than the composite mean of 3.89 implying that completion of building construction projects within budget moderately influenced implementation of building construction projects. The higher line item standard deviation 0.81 than the composite standard deviation 0.46 indicates divergent views.

The study also sought to establish if during the implementation they had minimal project variation orders in statement 5 . The findings show that out of the 221 respondents, 21(9.5\%) strongly agreed, 164(74.2\%) agreed, $17(7.7 \%)$ were neutral, $12(5.4 \%)$ disagreed while $7(3.2 \%)$ strongly disagreed. The mean was 3.81 with a standard deviation of 0.80 . This shows that the line item mean was lower than the composite mean of 3.89 meaning that minimal project variations does not influence building construction projects. A higher line-item standard deviation of 0.80 than the composite standard deviation of 0.46 indicates divergent opinions.

The respondents were asked to indicate their level of agreement with a statement on having to rework on completed projects in statement 6 . Based on this, 34(15.4\%) of the respondents strongly agreed, 62(28.1\%) agreed, 26(11.8\%) were neutral, $63(28.5 \%)$ disagreed and $36(16.3 \%)$ of the respondents strongly disagreed. The mean score for the statement was 2.98 with a standard deviation of 1.36 . This line item mean of 2.98 was lower than the composite mean of 3.89, meaning that minimal rework on tasks already completed does not influence the implementation of building construction projects. Higher line standard deviation of 1.36 than the composite standard deviation of 0.46 shows existence of divergent opinions among the respondents.

On statement 7, we meet quality specifications on construction projects, $73(33 \%)$ of the respondents strongly agreed, 131(59.3\%) agreed, $6(2.7 \%)$ disagreed while $11(5 \%)$ strongly disagreed. The mean response attained was 4.13 with a standard deviation of 0.94 . This shows that the respondents in general agreed with the statement. Given that the line item mean of 4.13 is greater than the composite mean of 3.89 , it is evident that the building construction projects meet the required quality specification. However, the line item standard deviation of 0.94 being higher than the composite standard deviation of 0.46 , shows that there were divergent opinions among the respondents with regard to the statement.

On statement 8 , that quality checks are carried out on materials, $80(36.2 \%)$ strongly agreed, $120(54.3 \%)$ agreed, $6(2.7 \%)$ were neutral, $9(4.1 \%)$ disagreed while $6(2.7 \%)$ strongly disagreed. The mean was 4.17 with a standard deviation of 0.88 . This shows that the respondents were in agreement with the statement, given that the line item mean of 4.17 was higher than the composite mean of 3.89, it implies that quality checks of materials influence implementation of building construction projects. However, higher line item standard deviation of 0.88 , than the composite standard deviation of 0.46 , shows some divergence in views of the respondents.

On statement 9, that County Government was satisfied with the work performance. Results show that 72(32.6\%) strongly agreed, $134(60.6 \%)$ agreed, $4(1.8 \%)$ were neutral, 5(2.3\%) disagreed and 6(2.7\%) strongly disagreed. The mean score was 4.18 with a standard deviation of 0.81 . This indicates that the respondents agreed with the statement in general given that the line item mean of 4.18 was higher than the composite mean of 3.89 shows that the County Government was satisfied with the building projects handed over to them in Kajiado County. However, the higher line standard deviation of 0.81 compared to the composite standard deviation of 0.46 indicates that there exists some divergent opinion as displayed by neutral, disagree and strongly disagree in Table 5 .

On statement 10, that we meet clients' requirements/needs, 109(49.3\%) strongly agreed, 100(45.2\%) agreed, $6(2.7 \%)$ disagreed and $6(2.7 \%)$ strongly disagreed. The mean score attained was 4.36 with a standard deviation of 0.85 . These findings indicate that respondents strongly agreed with the statement on clients' satisfaction. This is confirmed by the line item mean of 4.36 being higher than the composite mean of 3.89 Hence, it can be concluded that workers in the building construction projects in Kajiado County are satisfied with the work they do. However, a higher line item standard deviation of 0.85 than the composite standard deviation of 0.46 indicated that some divergence in opinions existed.

On statement 11, that we are satisfied with management of projects, $96(43.4 \%)$ strongly agreed with the statement, $113(51.1 \%)$ agreed, $2(0.9 \%)$ were neutral, $4(1.8 \%)$ disagreed while $6(2.7 \%)$ strongly disagreed. The mean score was 4.31 with a standard deviation of 0.82 . It shows that respondents strongly agreed with the statement and given that the line item mean of 4.31 was higher than the composite mean of 3.89 , it can be concluded that the respondents were satisfied with the way building projects are being managed in Kajiado County. However, the higher line item 
standard deviation of 0.82 than the composite standard deviation of 0.46 indicates divergent opinion on some respondents.

Interviews were carried out with site engineers and project managers. When asked whether they would complete the project within the time frame. This is what they had to say;

"I mostly make sure the projects I head are completed within the requisite time, the issue of delaying works so as to seek extension and probably more funding for the same project spoils the reputation of most contractors and engineers." (Engineer 1).

Few of the responses were of the contrary opinion. One of them emphatically said that:

"No, most of the time the projects are not completed in time, not due to the shortcomings of the project engineers and contractors but mostly due to delays in the county government in releasing funds to cater for all the project requirements." (Engineer 3)

This response was reaffirmed by another who said that,

"This project has taken too long to complete because of the county government bureaucracies, approvals usually take a lot of time, ending up delaying the whole process." (Engineer 4)

On issues regarding the completion of project within budget, the responses from the site engineers were mixed. There was an indication that most projects which do not finish within the prescribed budget had reasons beyond their scope. One of the key responses from the site engineers was that,

"I have a feeling this particular project will not have a cost overrun, we are very optimistic that we will clear everything within the budget set by the county government, if anything, maybe a variation of around $11 \%$ only." (Engineer 1)

However, another site engineer interviewed indicated ways of ensuring checks on cost are implemented. He therefore said that;

"We meet every fortnight to look at the progress in the implementation, the challenges that we face as a team, and the expectations, and then do the necessary adjustments if need be." (Engineer 5)

On satisfaction of clients, majority of the site engineers agreed that the client was satisfied with their work performance. One respondent said thus,

"We have been working with the county government and our name is good there due the good service we offer. We achieve goals well and our quality and time is good." (Engineer 3)

On workers' satisfaction, when asked about the level of satisfaction of their workers, and if they practiced recognition and rewarding of the high performing workers. The key responses from site engineers were positive. One respondent said that

"Our workers are satisfied with the working conditions, we allow then breaks so that they can have meals and refresh themselves, they have never complained about it." (Engineer 4)

The site engineers indicated efforts were put in place to ensure satisfaction, thus,

"We usually appraise our workers then reward the best performing one by giving then supervisory roles which is accompanied by an increment in their wages. Majority of them appreciate the kind of motivation we offer and are usually satisfied" (Engineer 3)

These findings are in line with the findings of Wi and Jung (2010) who agreed that the traditional measures of project implementation are the aspects of time, budget and quality of the final project delivered to the owner. It also agrees with the findings of Durdyev et al., (2017) who attributed delays in payment of contractors to the delay in timely project completion. With regard to satisfaction of the owner, the project found that the County Government of Kajiado, which was the client, was satisfied with the quality of the project delivered, this agrees with the findings of Liu and Walker (1998) who posited that satisfaction is one of the attributes of project success, it is importance for the owner to be satisfied with the final project delivered, as it acts as a measure of project team performance.

\subsection{Project Team Knowledge Diversity and Implementation of Building Construction Projects}

The objective of the study was to determine the influence of project team knowledge diversity on the implementation of building construction projects in Kajiado County. Data was collected and analyzed both descriptively and inferentially. Respondents were required to respond to items asking them to state the extent to 
which they agreed or disagreed with the statements. The items were based on a five-point Likert scale of $1-5$ where; 5 - Strongly Agree, 4 - Agree, 3 - Neutral, 2 - Disagree, and 1 - Strongly Disagree. The results are shown in Table 6.

Table 6. Project team knowledge diversity and implementation of building construction projects

\begin{tabular}{|c|c|c|c|c|c|c|c|c|}
\hline & Statements & SA & $\mathrm{A}$ & $\mathrm{N}$ & $\mathrm{D}$ & SD & Mean & $\begin{array}{l}\text { Std. } \\
\text { Dev. }\end{array}$ \\
\hline \multirow[t]{2}{*}{1} & Recruitment of workers into the project is & 42 & 152 & 9 & 14 & 4 & 3.97 & 0.81 \\
\hline & based on their education level & $19.0 \%$ & $68.8 \%$ & $4.1 \%$ & $6.3 \%$ & $1.8 \%$ & & \\
\hline \multirow[t]{2}{*}{2} & I have had challenges working with people & 18 & 46 & 11 & 97 & 49 & 2.49 & 1.27 \\
\hline & from different education levels & $8.1 \%$ & $20.8 \%$ & $5.0 \%$ & $43.9 \%$ & $22.2 \%$ & & \\
\hline \multirow[t]{2}{*}{3} & $\begin{array}{l}\text { Equal opportunities for job advancement exist } \\
\text { for workers with both most and least education }\end{array}$ & 38 & 153 & 13 & 11 & 6 & 3.93 & 0.82 \\
\hline & levels & $17.2 \%$ & $69.2 \%$ & $5.9 \%$ & $5.0 \%$ & $2.7 \%$ & & \\
\hline \multirow[t]{2}{*}{4} & Differences in education levels of workers is a & 10 & 25 & 16 & 112 & 58 & 2.17 & 1.08 \\
\hline & & $4.5 \%$ & $11.3 \%$ & $7.3 \%$ & $50.7 \%$ & $26.2 \%$ & & \\
\hline \multirow[t]{2}{*}{5} & Jobs are allocated depending on skills of an & 126 & 84 & 3 & 6 & 2 & 4.48 & 0.74 \\
\hline & & $57.0 \%$ & $38.0 \%$ & $1.4 \%$ & $2.7 \%$ & $0.9 \%$ & & \\
\hline \multirow[t]{2}{*}{6} & Payment is made based on skills possessed & 122 & 85 & 3 & 11 & 0 & 4.44 & 0.76 \\
\hline & & $55.2 \%$ & $38.4 \%$ & $1.4 \%$ & $5.0 \%$ & $0.0 \%$ & & \\
\hline \multirow[t]{2}{*}{7} & At work, I experience lack of confidence due to & 34 & 21 & 15 & 128 & 23 & 2.62 & 1.25 \\
\hline & my level of skills & $15.4 \%$ & $9.5 \%$ & $6.8 \%$ & $57.9 \%$ & $10.4 \%$ & & \\
\hline \multirow[t]{2}{*}{8} & Learning more skills through training, would & 76 & 123 & 5 & 14 & 3 & 4.15 & 0.85 \\
\hline & improve my work performance & $34.4 \%$ & $55.7 \%$ & $2.3 \%$ & $6.3 \%$ & $1.3 \%$ & & \\
\hline \multirow[t]{2}{*}{9} & $\begin{array}{l}\text { The team leader includes members of different } \\
\text { training backgrounds in decision making }\end{array}$ & 58 & 144 & 5 & 14 & 0 & 4.11 & 0.73 \\
\hline & process & $26.2 \%$ & $65.2 \%$ & $2.3 \%$ & $6.3 \%$ & $0.0 \%$ & & \\
\hline \multirow[t]{4}{*}{10} & Mentoring of workers in acquiring jobs skills in & 31 & 144 & 11 & 30 & 5 & 3.75 & 0.94 \\
\hline & latest technologies is highly practiced in this & & & & & & & \\
\hline & company & $14.0 \%$ & $65.2 \%$ & $5.0 \%$ & $13.5 \%$ & $2.3 \%$ & & \\
\hline & Composite Mean and Std. Deviation & & & & & & 3.61 & 0.37 \\
\hline
\end{tabular}

Table 6 show results from a descriptive analysis of statements relating to project team knowledge diversity. Statement 1, that recruitment of workers into the project is based on education levels of the workers. Out of the 221 respondents who participated in the study, $42(19 \%)$ of the respondents strongly agreed, $152(68.8 \%)$ agreed, 
$9(4.1 \%)$ were neutral $14(6.3 \%)$ disagreed and $4(1.8 \%)$ strongly disagreed. The mean response was 3.97 with a standard deviation of 0.81 . This shows that the respondents agreed with that statement, given that the line item mean of 3.97 was higher than the composite mean of 3.61. This implies that respondents agree that recruitment of workers is based on levels of education. However, a higher line item standard deviation of 0.81 than the composite standard deviation of 0.37 suggests that there was some divergence in views of some of the respondents.

On statement 2, respondents were asked to indicate their level of agreement on whether they had challenges working with people of different education levels. Based on this, $18(8.1 \%)$ respondents strongly agreed, $46(20.8 \%)$ agreed, 11(5\%) were neutral, 97(43.9\%) disagreed while $49(22.2 \%)$ strongly disagreed. The mean score was 2.49 with a standard deviation of 1.27 , this shows that the respondents disagreed with the statement. This is confirmed with line item mean of 2.49 being lower than the composite mean of 3.61. However, the higher line item standard deviation of 1.27 than the composite standard deviation of 0.37 indicates a divergence in opinions.

Information on statement 3 that equal opportunities for job advancement exist for all workers, 38(17.2\%) respondents strongly agreed, 153(69.2\%) agreed, 13(5.9\%) were neutral, $11(5 \%)$ disagreed and $6(2.7 \%)$ strongly disagreed. The mean score was 3.93 with a standard deviation of 0.82 , this was higher than the composite mean of 3.61 indicating that majority of the respondents moderately agreed with the statement. This is anticipated to motivate implementation of construction projects. However, higher line item standard deviation of 0.82 than the composite standard deviation of 0.37 indicates variability of opinions.

Statement 4 that difference in education level of workers is a source of conflict, 10(4.5\%) of the respondents strongly agreed, 25(11.3\%) agreed, 16(7.2\%) were neutral, 112(50.7\%) disagreed while 58(26.2\%) strongly disagreed. The mean score was 2.17 with a standard deviation of 1.08 . This shows that the respondents disagreed with the statement given that the line item mean of 2.71 was lower than the composite mean of 3.61. This means that the difference in education levels of workers does affect implementation of building construction projects. However, the higher line item standard deviation of 1.08 than the composite standard deviation of 0.37 shows divergence of opinions.

On statement 5 that jobs are allocated depending on skills of individual workers, 126(57\%) strongly agreed with the statement, $84(38 \%)$ agreed, $3(1.4 \%)$ were neutral, $6(2.7 \%)$ disagreed while $2(0.9 \%)$ strongly disagreed. The mean response was 4.48 with a standard deviation of 0.74 which indicates that the respondents strongly agreed with the statement. This is evidenced by line item mean of 4.48 being higher than the composite mean of 3.61. This is likely to influence implementation of building construction projects in Kajiado County. However, a higher line item standard deviation of 0.74 than the composite standard deviation 0.37 indicates divergence of view.

On statement 6 that payment is made based on skills possessed, 122(55.2\%) of the respondents strongly agreed, $85(38.5 \%)$ agreed, $3(1.4 \%)$ were neutral and $11(5 \%)$ of the respondents disagreed with the statement. The mean score was 4.44 with a standard deviation of 0.76 , this shows that the respondents strongly agreed with the statement. This is confirmed by the line item mean of 4.44 being higher than the composite mean of 3.61, implying that this influences implementation of building construction projects in a positive manner. The higher line item standard deviation of 0.76 in comparison to the composite standard deviation of 0.37 , shows variability in the respondents' views.

Statement 7, that at work I experience lack of confidence due to my level of skills, 34(15.4\%) respondents strongly agreed, 21(9.5\%) agreed, 15(6.8\%) were neutral, 128(57.9\%) disagreed and 23(10.4\%) of the respondents strongly disagreed. The mean response was 2.62 with a standard deviation of 1.25 , this shows that the respondents disagreed with the statement. This is in line given that the line item mean 2.62 is lower than the composite mean of 3.61. this implies that the line item does not affect implementation of building construction projects. However, a higher line item standard deviation of 1.25 compared to the composite standard deviation indicates variability in opinion.

Statement 8, that learning more skills through training would improve my work performance, $76(34.4 \%)$ of the respondents strongly agreed, $123(55.7 \%)$ agreed, $5(2.3 \%)$ were neutral, $14(6.3 \%)$ disagreed while $3(1.4 \%)$ strongly disagreed. The mean score was 4.15 with a standard deviation of 0.85 , this shows that the respondents agreed with the statement. Given that the line item mean of 4.15 is greater than the composite mean of 3.61, it shows that this statement influences the implementation of building construction projects in a positive manner. However, a higher line item standard deviation of 0.85 than the composite standard deviation of 0.37 indicates variability of views.

Statement 9, that team leaders include members of different training background in decision-making process showed that, 58(26.2\%) strongly agreed, 144(65.2\%) agreed, 5(2.3\%) were neutral, and 14(6.3\%) disagreed with the statement. The mean score was 4.11 with standard deviation 0.73 indicating that the respondents agreed with the statement. This line item mean of 4.11 was higher than the composite mean of 3.61 , meaning the line item 
influences the implementation of building construction projects positively. Higher standard deviation of 0.73 shows variation in opinion.

Statement 10, that mentoring of workers in acquiring job skills in latest technologies is highly applied in the company show that 31(14\%) strongly agreed, 144(65.2\%) agreed, 11(5\%) were neutral, 30(13.6\%) disagreed and $5(2.3 \%)$ strongly disagreed. A mean of 3.75 was attained with a standard deviation of 0.94 , showing that respondents agreed with the statement. This indicates that new skills mentorship is appreciated in the building construction projects in Kajiado County. However, a higher line item standard deviation of 0.94 than the composite standard deviation of 0.37 shows variability of opinion by some respondents.

In-depth interviews were carried out with site engineers on project team knowledge diversity on implementation of building construction projects in Kajiado county. This is what they had to say:

"It is easier to work with workers who are well trained in their different fields because you don't waste time trying to explain to them what they are supposed to do. Minimal supervision is required." (Engineer 5)

These sentiments were echoed by another site engineer who said that:

"I have people of different education backgrounds here, and they work together in harmony towards achievement of the project objective. We allocate them tasks depending on their level of education and even pay them depending on their skills level." (Engineer 3)

On issues regarding decision making, one site engineer said:

"Every evening after we have finished the day's work, we usually have a meeting to evaluate the achievements for the day then plan for the next day. If there are decisions to be made regarding the project, I seek the opinion of almost everyone before arriving at the final decision, so that the workers feel some sense of ownership of the project." (Engineer 4)

\subsection{Correlational Analysis of Project Team Knowledge Diversity and Implementation of Building Construction Projects}

Further analysis was carried out to ascertain the strength of relationship between project team knowledge diversity and implementation of building construction projects. A correlational analysis using the Karl Pearson method was done and the results presented in Table 7.

Table 7. Correlation between project team knowledge diversity and implementation of building construction projects

\begin{tabular}{lll}
\hline Variable & & Project Team Knowledge Diversity \\
\hline Implementation of Building & Pearson Correlation & $0.323^{*}$ \\
Construction Projects & Sig. (2-tailed) & 0.000 \\
& $\mathrm{n}$ & 221 \\
\hline
\end{tabular}

* Correlation is significant at the 0.05 level (2-tailed)

Table 7 shows that there exists a moderate positive correlation between project team knowledge diversity and implementation of building construction projects as depicted by a correlation coefficient of 0.323 . The Pearson correlation coefficient is significant since the p-value 0.000 is less than 0.05 level of significance. This implies an improvement in knowledge diversity leads to an improvement in the implementation of building construction projects. The significance level was measured at $5 \%$ indicating that there is a significant relationship between Project team knowledge diversity and implementation of building construction projects leading to the rejection of the null hypothesis $\left(\mathrm{H}_{0}\right.$ : There is no significant relationship between project team knowledge diversity and implementation of building construction projects) and accepting the alternative hypothesis, and therefore, the research findings concluded that there was a significant relationship between project team knowledge diversity and implementation of building construction projects. These findings are in agreement with the findings of Shin et al., (2012) who claimed that with knowledge diversity, team members are more likely to utilize a variety of perspectives, ideas, and expertise of other team members to generate novel and creative ideas in a context requiring 
creativity and hence enhance team performance which, in turn leads to successful implementation of projects. The results also agree with Gong et al., (2013) who argued that diverse knowledge increases mutual understanding of team members and facilitates the motivation to learn from one another which is an important aspect of team performance. The findings do not agree with those of Ogubazghi and Muturi (2014) who claimed that diversity in knowledge among project directors might bring about conflict which will hinder the success implementation of projects.

\subsection{Regression Analysis of Project Team Knowledge Diversity on Implementation of Building Construction Projects}

To ascertain the contribution of project team knowledge diversity on the implementation of building construction projects, a regression analysis was run and the results presented in various sub-themes as follows:

5.6.1 Model Summary of Regression of Project Team Knowledge Diversity and Implementation of Building Construction Projects

The model summary sought to establish how project team knowledge diversity as a predictor significantly or insignificantly predicted implementation of building construction projects. The regression model summary is presented in Table 8.

Table 8 . Model summary of project team knowledge diversity

\begin{tabular}{|c|c|c|c|c|c|c|c|c|c|}
\hline \multirow[t]{3}{*}{ Model } & \multirow[t]{3}{*}{$\mathrm{R}$} & \multirow{3}{*}{$\begin{array}{c}\mathrm{R} \\
\text { Square }\end{array}$} & \multirow{3}{*}{$\begin{array}{l}\text { Adjusted } \\
\text { R Square }\end{array}$} & \multirow{3}{*}{$\begin{array}{l}\text { Std. Error } \\
\text { of the } \\
\text { Estimate }\end{array}$} & \multicolumn{5}{|c|}{ Change Statistics } \\
\hline & & & & & R Square & $\mathrm{F}$ & & & Sig. F \\
\hline & & & & & Change & Change & dfl & df2 & Change \\
\hline 1 & $0.323^{\mathrm{a}}$ & 0.104 & 0.100 & 0.52424 & 0.104 & 25.522 & 1 & 219 & 0.000 \\
\hline
\end{tabular}

a. Predictors: (Constant), Project Team Knowledge Diversity

The model summary Table 8 proposed that there was a positive correlation $(\mathrm{R}=0.323)$ between project team knowledge diversity and implementation of building construction projects with those predicted by the regression model. Additionally, $10.4 \%$ of the variation in the implementation of building construction projects was explained by project team knowledge diversity. The rest $(89.6 \%)$ is explained by variables not in the model.

5.6.2 ANOVA of the Regression of Project Team Knowledge Diversity and Implementation of Building Construction Projects

The study aimed at establishing if the regression model was best match for predicting implementation of building construction projects after employing project team knowledge diversity. The results of the regression coefficient are presented in Table 9.

Table 9. ANOVA of the regression of project team knowledge diversity and implementation of building construction projects

\begin{tabular}{llccccc}
\hline Model & & Sum of Squares & df & Mean Square & F & Sig. \\
\hline 1 & Regression & 7.014 & 1 & 7.014 & 25.522 & $0.000^{\mathrm{b}}$ \\
& Residual & 60.187 & 219 & 0.275 & & \\
& Total & 67.201 & 220 & & & \\
\hline
\end{tabular}

a. Dependent Variable: Implementation of Building Construction Projects

b. Predictors: (Constant), Project Team Knowledge Diversity

Table 9 shows that the ANOVA results pointed out that the F-statistic $(1,219)=25.522$ is significant at $p-$ value $0.000<0.05$, indicating that the predictor coefficient was different from zero, and hence the regression model results were a better predictor of implementation of building construction projects after use of project team knowledge diversity. The findings of the research are in line with studies by Kristinsson et al. (2016), whose findings indicated the existence of a positive relationship between diversity in knowledge in team members and the level of innovation in the team. They particularly indicated that team with diverse knowledge generate and share ideas that are can be implemented into new products and services. Kotur and Anbazhagan (2014) also looked 
at how education and experience diversity in project team members influence the performance of teams during implementation of projects. They concluded that projects which have teams having heterogeny in knowledge performed better than homogeneous teams.

5.6.3 Regression Coefficient of Project Team Knowledge Diversity and Implementation of Building Construction Projects

The objective of the study was to determine whether diversity of knowledge in project team members influenced the process of implementation of building construction projects. The regression coefficient results are presented in Table 10.

Table 10. Regression coefficient of project team knowledge diversity on implementation of building construction projects

Coefficient

\begin{tabular}{llccccc}
\hline \multirow{2}{*}{ Model } & \multicolumn{7}{c}{$\begin{array}{c}\text { Standardized } \\
\text { Coefficients } \\
\end{array}$} & & \multicolumn{7}{c}{ Unstandardized Coefficients } & B & Sig. \\
\hline 1 & (Constant) & 2.193 & 0.337 & & 6.508 & 0.000 \\
& Project Team & 0.471 & 0.093 & 0.323 & 5.052 & 0.000 \\
& Knowledge & & & & & \\
& Diversity & & & & & \\
& & &
\end{tabular}

a. Dependent Variable: Implementation of Building Construction Projects

The simple linear regression results in Table 10 suggest that there was consequential influence of project team knowledge diversity on implementation of building construction projects. The coefficient constant terms $\left(\beta_{0}=\right.$ $2.193, p<0.05)$ and project team knowledge diversity $\left.\beta_{1}=0.471, p<0.05\right)$ were statistically significant. The regression model for implementation of building construction projects on project team knowledge diversity was $Y=2.193+0.471 X_{1}$ indicating that for each unit of project team knowledge diversity, implementation of building construction projects is marginally transformed by 0.471 units. It was therefore, concluded that project team knowledge diversity and implementation of building construction projects are positively and linearly related.

\section{Conclusion}

The study sought to determine the influence of project team knowledge diversity on the process of implementation of building construction projects in Kajiado County. The operators for project team knowledge diversity were; team member education level, team member specialty, team member skills, team member experience and team member training. Descriptive statistics showed that the respondents agreed that knowledge diversity in project team members influenced the process of implementation of building construction projects. The study showed that skills among the workers was appreciated, and had a positive influence on the implementation of building construction projects, since it determined job allocation, remuneration and confidence of the workers. It is therefore, important that for a project to be implemented successfully, the project team should have members with diversity in skills. Diversity in levels of education does not seem to influence the implementation of building construction projects much. Results from inferential statistics indicate that project team knowledge diversity had a positive influence on the implementation of building construction projects. This means that building construction projects that have a mix of workers with divergent knowledge would be implemented better than those that do not.

\section{Recommendation}

The study makes the following recommendations based on the findings. Regarding policy, it was showed that diversity in knowledge in project team members significant influence the implementation process of building construction process in a positive way, this implies that if building construction companies employ a workforce that is diverse in terms of knowledge, then projects would be implemented successfully. Further it implies that building construction companies' managers should look at ways of managing the interpersonal conflict between the project team members. This would reduce the conflict between project team members and hence improve the implementation of building construction projects. Additionally, building construction companies should enhance integration and equity among the project team members based on knowledge diversity for successful 
implementation of projects in Kajiado County, and by extension would enhance satisfaction of all stakeholders.

\section{Limitations}

The study gathered information on project team knowledge diversity and implementation of building construction projects in Kajiado county, Kenya. The county is expansive in size and building construction projects implemented by the county government are spread all-over, due to the remoteness of some places, the respondents were only sampled from places that were easier to reach. The nature of the information needed for the study was considered to be sensitive by some respondents, hence this could have led to biased responses even after being assured of their anonymity in the entire research.

\section{References}

Ahsan, K., \& Gunawan, I. (2010). Analysis of cost and schedule performance of international development projects. International Journal of Project Management, 28(1), 68-78. https://doi.org/10.1016/j.ijproman.2009.03.005

Barclay, C., \& Osei-Bryson, K.-M. (2010). Project performance development framework: An approach for developing performance criteria \& measures for information systems (IS) projects. International Journal of Production Economics, 124(1), 272-292. https://doi.org/10.1016/j.ijpe.2009.11.025

Bhattacherjee, A. (2012). Social science research: Principles, methods, and practices.

Bodla, A. A., Tang, N., Jiang, W., \& Tian, L. (2018). Diversity and creativity in cross-national teams: The role of team knowledge sharing and inclusive climate. Journal of Management \& Organization, 24(5), 711-729. https://doi.org/10.1017/jmo.2016.34

Chan, A. P., Chan, D. W., Chiang, Y. H., Tang, B.-S., Chan, E. H., \& Ho, K. S. (2004). Exploring critical success factors for partnering in construction projects. Journal of Construction Engineering and Management, 130(2), 188-198. https://doi.org/10.1061/(ASCE)0733-9364(2004)130:2(188)

Chan, A. P., Ho, D. C., \& Tam, C. M. (2001). Design and build project success factors: Multivariate analysis. Journal of Construction Engineering and Management, 127(2), 93-100. https://doi.org/10.1061/(ASCE)0733-9364(2001)127:2(93)

Chan, A. P., Ma, X., Yi, W., Zhou, X., \& Xiong, F. (2018). Critical review of studies on building information modeling (BIM) in project management.

Copen, C. E., \& Silverstein, M. (2008). The Transmission of Religious Beliefs across Generations: Do Grandparents Matter? Journal of Comparative Family Studies, 39(1), 59-71. https://doi.org/10.3138/jcfs.39.1.59

Diallo, A., \& Thuillier, D. (2004). The success dimensions of international development projects: The perceptions of African project coordinators. International Journal of Project Management, 22(1), 19-31. https://doi.org/10.1016/S0263-7863(03)00008-5

Dulaimi, M. F. (2005). The influence of academic education and formal training on the project manager's behavior. Journal of Construction Research, 6(01), 179-193. https://doi.org/10.1142/S1609945105000328

Durdyev, S., Omarov, M., \& Ismail, S. (2017). Causes of delay in residential construction projects in Cambodia. Cogent Engineering, 4(1), 1291117. https://doi.org/10.1080/23311916.2017.1291117

Freeman, M., \& Beale, P. (1992). Measuring project success.

Gong, Y., Kim, T.-Y., Lee, D.-R., \& Zhu, J. (2013). A multilevel model of team goal orientation, information exchange, and creativity. Academy of Management Journal, 56(3), 827-851. https://doi.org/10.5465/amj.2011.0177

Hu, M.-L. M. (2009). Knowledge sharing and innovative service behavior relationship: Guanxi as mediator. Social Behavior and Personality: An International Journal, 37(7), 977-992. https://doi.org/10.2224/sbp.2009.37.7.977

Huang, X., Hsieh, J. J., \& He, W. (2014). Expertise dissimilarity and creativity: The contingent roles of tacit and explicit knowledge sharing. Journal of Applied Psychology, 99(5), 816. https://doi.org/10.1037/a0036911

Jetten, J., Spears, R., \& Manstead, A. S. (1998). Defining dimensions of distinctiveness: Group variability makes a difference to differentiation. Journal of Personality and Social Psychology, 74(6), 1481. https://doi.org/10.1037/0022-3514.74.6.1481

Kariuki, J. T. (2018). The effect of project manager's leadership style on performance of water projects in Kenya. 
European Scientific Journal, 14(17), 33-45. https://doi.org/10.19044/esj.2018.v14n17p33

Khan, M. (2012). The impact of training and motivation on performance of employees. Business Review, 7(2), 84 95.

Klagegg, O. J., Samset, K., \& Magnussen, O. M. (2005). Improving Success in Public Investment Projects: Lessons from Government Initiative in Norway to Improve Quality at Entry. 19th IPMA World Congress.

Kotur, B. R., \& Anbazhagan, S. (2014). Education and work-experience-influence on the performance. Journal of Business and Management, 16(5), 104-110. https://doi.org/10.9790/487X-1653104110

Kristinsson, K., Candi, M., \& Sæmundsson, R. J. (2016). The relationship between founder team diversity and innovation performance: The moderating role of causation logic. Long Range Planning, 49(4), 464-476. https://doi.org/10.1016/j.lrp.2015.12.013

Lim, C. S., \& Mohamed, M. Z. (1999). Criteria of project success: An exploratory re-examination. International Journal of Project Management, 17(4), 243-248. https://doi.org/10.1016/S0263-7863(98)00040-4

Liu, A. M., \& Walker, A. (1998). Evaluation of project outcomes. Construction Management \& Economics, 16(2), 209-219. https://doi.org/10.1080/014461998372493

Lovelace, K., Shapiro, D. L., \& Weingart, L. R. (2001). Maximizing cross-functional new product teams' innovativeness and constraint adherence: A conflict communications perspective. Academy of Management Journal, 44(4), 779-793. https://doi.org/10.2307/3069415

Machlis, G. E., Force, J. E., \& Burch Jr, W. R. (1997). The human ecosystem part I: The human ecosystem as an organizing concept in ecosystem management. Society \& Natural Resources, 10(4), 347-367. https://doi.org/10.1080/08941929709381034

Milberg, C., \& Walsh, K. D. (2012). Exploring lean construction practice, research, and education. Engineering, Construction and Architectural Management.

Mugenda, O. M., \& Mugenda, G. (2003). Research Methods. Research Methods.

Myaskovsky, L., Unikel, E., \& Dew, M. A. (2005). Effects of gender diversity on performance and interpersonal behavior in small work groups. Sex Roles, 52(9), 645-657. https://doi.org/10.1007/s11199-005-3732-8

Naqvi, S. R., Ishtiaq, M., Kanwal, N., Butt, M. U., \& Nawaz, S. (2013). Impact of gender diversity on team performance: The moderating role of organizational culture in telecom sector of Pakistan. Asian Journal of Social Sciences \& Humanities, 2(4), 228-235.

Odum, H. T. (1953). Factors controlling marine invasion into Florida fresh waters. Bulletin of Marine Science, 3(2), 134-156.

Ofori, D. F. (2013). Project management practices and critical success factors-A developing country perspective. International Journal of Business and Management, 8(21), 14. https://doi.org/10.5539/ijbm.v8n21p14

Ogubazghi, S. K., \& Muturi, W. (2014). The effect of age and educational level of owner/managers on SMMEs' access to bank loan in Eritrea: Evidence from Asmara City. American Journal of Industrial and Business Management, 4(11), 632. https://doi.org/10.4236/ajibm.2014.411069

Rutterford, C., Copas, A., \& Eldridge, S. (2015). Methods for sample size determination in cluster randomized trials. International Journal of Epidemiology, 44(3), 1051-1067. https://doi.org/10.1093/ije/dyv113

Saunders, M., Lewis, P., \& Thornhill, A. (2003). Research methods for business students. Essex: Prentice Hall: Financial Times.

Shin, S. J., Kim, T.-Y., Lee, J.-Y., \& Bian, L. (2012). Cognitive team diversity and individual team member creativity: A cross-level interaction. Academy of Management Journal, 55(1), 197-212. https://doi.org/10.5465/amj.2010.0270

Thiong'o, D. M., \& Muchelule, D. (2019). Effect of Building Information Modelling On Construction Projects Risks Management in Kenya. American Based Research Journal, 8(10).

Valls, V., González-Romá, V., \& Tomás, I. (2016). Linking educational diversity and team performance: Team communication quality and innovation team climate matter. Journal of Occupational and Organizational Psychology, 89(4), 751-771. https://doi.org/10.1111/joop.12152

Van Niekerk, S. I., \& Steyn, H. (2011). Defining 'project success' for a complex project-The case of a nuclear engineering development. South African Journal of Industrial Engineering, 22(1), 123-136. 
https://doi.org/10.7166/22-1-38

Wi, H., \& Jung, M. (2010). Modeling and analysis of project performance factors in an extended project-oriented virtual organization (EProVO). Expert Systems with Applications, 37(2), 1143-1151. https://doi.org/10.1016/j.eswa.2009.06.051

Yalegama, S., Chileshe, N., \& Ma, T. (2016). Critical success factors for community-driven development projects: A Sri Lankan community perspective. International Journal of Project Management, 34(4), 643-659. https://doi.org/10.1016/j.ijproman.2016.02.006

Zhang, X., Wu, Y., Shen, L., \& Skitmore, M. (2014). A prototype system dynamic model for assessing the sustainability of construction projects. International Journal of Project Management, 32(1), 66-76. https://doi.org/10.1016/j.ijproman.2013.01.009

\section{Copyrights}

Copyright for this article is retained by the author(s), with first publication rights granted to the journal.

This is an open-access article distributed under the terms and conditions of the Creative Commons Attribution license (http://creativecommons.org/licenses/by/4.0/). 